Journal of Behavioral Decision Making

J. Behav. Dec. Making, 21: 493-518 (2008)

Published online 8 May 2008 in Wiley InterScience

(www.interscience.wiley.com) DOI: 10.1002/bdm.598

\title{
The Description-Experience Gap in Risky Choice: The Role of Sample Size and Experienced Probabilities
}

\author{
ROBIN HAU ${ }^{1 *}$, TIMOTHY J. PLESKAC ${ }^{2}$, \\ JÜRGEN KIEFER ${ }^{3}$ and RALPH HERTWIG ${ }^{1}$ \\ ${ }^{1}$ Department of Psychology, University of Basel, Switzerland \\ ${ }^{2}$ Department of Psychology, Michigan State University, USA \\ ${ }^{3}$ Center of Human-Machine-Systems, Technical University, Berlin, Germany
}

\begin{abstract}
Risky prospects come in different forms. Sometimes options are presented with convenient descriptions summarizing outcomes and their respective likelihoods. People can thus make decisions from description. In other cases people must call on their encounters with such prospects, making decisions from experience. Recent studies report a systematic and large description-experience gap. One key determinant of this gap is people's tendency to rely on small samples resulting in substantial sampling error. Here we examine whether this gap exists even when people draw on large samples. Although smaller, the gap persists. We use the choices of the present and previous studies to test a large set of candidate strategies that model decisions from experience, including 12 heuristics, two associative-learning models and the two-stage model of cumulative prospect theory. This model analysis suggests - as one explanation for the remaining description-experience gap in large samples - that people treat probabilities differently in both types of decisions. Copyright (C) 2008 John Wiley \& Sons, Ltd.
\end{abstract}

KEY WORDS decision from experience; heuristics; risky choice; sampling

\section{INTRODUCTION}

Experience matters. Although this statement sounds like a banal cliché, there is a steadily increasing body of research suggesting that cognitive processes and overt behavior depend on whether information is acquired through personal experience or by descriptive summaries of events. Consider, for instance, Bayesian reasoning. When base rates have been directly experienced they are more likely to be used than when symbolically described with a single summary statistic (e.g., Koehler, 1996; Weber, Böckenholt, Hilton, \& Wallace, 1993). Risk perception provides another instance of a description-experience gap. Israeli residents living in an area that experienced repeated terrorist attacks were found to be more risk seeking than

\footnotetext{
* Correspondence to: Robin Hau, Department of Psychology, University of Basel, Missionsstrasse 64a, 4051 Basel, Switzerland.

E-mail: robin.hau@unibas.ch
} 
international tourists merely equipped with, albeit gruesome, descriptions of attacks (Yechiam, Barron, \& Erev, 2005).

Experience matters. Consider the disparities between experts' recommendations and actual insurance decisions. Insurance agents and insurance brochures provide dry facts and figures to potential clients about the risks of such events as flooding. Yet, people tend not to purchase insurance - unless legally required tofor events that occur with low frequency but have severe consequences (Anderson, 1974; Kunreuther, 2006; Slovic, Fischhoff, Lichtenstein, Corrigan, \& Combs, 1977). In 2005, for example, damage caused by hurricanes from the North Atlantic totaled around $\$ 165$ billion-only half of those losses were insured (Munich Re Group, 2006). One reason may be that dry facts and figures cannot take the place of authentic experience (but see Yechiam et al., 2005).

Experience matters - but why? There are a number of theoretical constructs that can help to explain why and how experienced information differs from symbolically described information. They range from the notion of psychological distance (Trope \& Liberman, 2003) to the speculation that directly experienced information invokes an implicit rather than an explicit learning system (Koehler, 1996). In this paper, we investigate a description-experience gap in risky decision-making. Specifically, we examine whether making experience- and description-based information increasingly equivalent also renders them psychologically equivalent. Second, we test an extensive set of candidate strategies that may underlie decisions from experience.

\section{THE DESCRIPTION-EXPERIENCE GAP IN CHOICES BETWEEN MONETARY GAMBLES}

Gambling problems have time and again played a key role in the development of theories of human choice. Luca Paccioli's problem of points (developed in 1494; cf. Hacking, 1975), the St. Petersburg paradox (Bernoulli, 1738/1954), the Allais paradox (Allais, 1953, 1979), and the Ellsberg paradox (Ellsberg, 1961) are just a few of the gambling problems that have instigated the development of the theories of mathematical probability and expectation, the expected utility theory, as well as descriptive alternatives to expected utility. When Savage (1954) proposed that virtually all alternative courses of action have risky, not perfectly predictable consequences and that everyday choices could be seen as equivalent to choices between monetary gambles, one of the longest lived and most frequently studied tasks in psychologists' (and economists') laboratories was born.

Since Edwards (1954), in his seminal paper, pioneered the study of preferences between monetary gambles in psychology the focus, however, has predominantly been on decisions made from description. In a recent meta-analysis of studies involving decisions between a two-outcome risky prospect and a sure thing (with equal expected value), Weber, Shafir, and Blais (2004) reported that all 20 studies (encompassing 226 choice situations) called for decisions between symbolically described gambles: That is, the outcomes of each option and their probabilities are provided, and the information is conveyed numerically, in terms of written probabilities, visual pie charts, or frequency distributions. Hertwig, Barron, Weber, and Erev (2004) referred to such decisions as decisions from description. Without any doubt, there are important real-world equivalents of such description-based decisions. When people have access to information such as newspaper weather forecasts, drug-package inserts, and mutual-fund brochures, all of which provide convenient descriptions of risky prospects, they can arrive at decisions from description.

These examples notwithstanding, people, businesses, and organizations often cannot help but make choices without resorting to summary descriptions of choice outcomes and probabilities. For instance, we cannot rely on descriptions of risky prospects in the countless mundane situations in which we decide whether or not to back up our computer hard drive, cross a busy street, or go out on a date. Being ignorant of the precise payoffs (outcomes and probabilities), however, we can draw small samples of experience, thus making decisions from experience (Hertwig et al., 2004). For instance, one sip of wine, perhaps even as little as a sniff 
or a look, determines whether the contents of the bottle are drinkable. Enjoying a 2-week free trial of a daily newspaper tells us whether it is to our political taste. A quick look on the online traffic cams tells us which route to choose for the morning commute. Glancing at the plates of the other guests helps us to determine which dish to choose from a restaurant's menu. Polling friends about which of two new movies they enjoyed renders our night at the movies more pleasurable.

Experience can come in different forms. For instance, it may be crystallized in terms of old experience with similar scenarios (see Klein, 1998; Tversky \& Fox, 1995). Alternatively, a person may have the opportunity to sample from his or her options, thus gaining novel experience. Hertwig et al.'s (2004) study illustrates how this foraging for information can be studied in the laboratory. Participants saw two buttons on a computer screen and were told that each button was associated with a payoff distribution. Clicking on a given button elicited the sampling of an outcome (with replacement) from its distribution. Respondents could sample in whatever order they desired. During this exploration, they neither earned nor lost any money. Instead, they simply learned about the properties of the distributions for a future choice. They were instructed to sample until they felt confident enough to decide which deck to choose in a final draw involving real monetary payoffs. Once they terminated sampling, they indicated their preferred option. Finally, respondents played out the selected option and received real payoffs. For illustration, a respondent may have sampled the sequences $\{3,3,3,3,3,3,3\}$ and $\{0,0,0,0,0,32,0,0,0,0\}$ from distributions $A$ and $B$, respectively. After these sequences, the respondent terminates sampling and indicates $A$ to be the preferred choice. One final random draw from distribution $A$ may result in outcome 3, reflecting the respondent's earnings in this choice.

\section{WHAT CAUSES THE DESCRIPTION-EXPERIENCE GAP?}

Hertwig et al. (2004) compared respondents' choices based on sampled experience with those of a second group who, responding to the same problems, made decisions from description. That is, information about outcomes and their probabilities were conveniently packaged and laid out in front of the participants. Choices differed drastically across groups. Description-based choices were consistent with prospect theory's assumption of overweighting of rare (low-probability) events (Kahneman \& Tversky, 1979). In contrast, in experience-based choices people chose as if the impact of objectively rare outcomes was attenuated compared both to the weight given in decisions from description and to the weight they deserved according to their objective probabilities.

Hertwig et al. (2004) identified two factors that appear to be behind the humble impact of rare events on people's choices. First, respondents' information search effort was correspondingly humble. Specifically, the total number of draws per decision problem was relatively small, with a median of 15 draws (17 draws in Weber et al.'s, 2004, decisions-from-experience study). Small samples exact an important consequence: Owing to the skewness of the binomial distribution with low $p$, small $n$ s make it more likely that a person encounters the rare event less frequently than expected $(n p)$ than more frequently than expected (for details see Hertwig, Barron, Weber, \& Erev, 2006). Second, Hertwig et al. (2004) reported that observations made late in the sequence of $n$ observations had more impact on the choice process than they deserved (i.e., more than $1 / n$ ). This recency effect makes the functional sample size of observations from which people derive their choice even smaller, thus further accentuating the underrepresentation of rare events.

In a comment to Hertwig et al. (2004), Fox and Hadar (2006) argued that "our internal analysis of [Hertwig et al.'s] data and our replication show that the so-called 'underweighting' of low-probability events in decisions from experience is driven almost entirely by a tendency to undersample low-probability events" (p. 161). In addition, Fox and Hadar used the two-stage model of cumulative prospect theory (Tversky \& Fox, 1995; Fox \& Tversky, 1998) to improve our understanding of decisions from experience. According to this model, people form a belief about the likelihoods of the outcomes of an uncertain option, and based on this evaluate the option. The latter step is modeled in terms of cumulative prospect theory's value and weighting 
functions (Tversky \& Kahneman, 1992). In the case of decisions from experience, Fox and Hadar used a person's experienced relative frequencies of events in the two distributions (e.g., 32 and 0 in option $B$ of the aforementioned example) as a proxy for the person's subjective belief. Then, they entered this belief into the value and weighting functions (using the median parameter estimates as specified in Tversky \& Kahneman). Thus applied, the two-stage model was reported to predict $69 \%$ of the individual choices in the Hertwig et al. data set. ${ }^{1}$

If sampling error is behind the description-experience gap-which, next to recency, was one of the two factors put forth by Hertwig et al. (2004) and emphasized by Fox and Hadar (2006) — this gap will be reduced to the extent that participants sample more. With larger samples, the sample probabilities are bound to resemble the objective probabilities more closely, thus providing a less distorted picture of the world. Alternatively, however, the description-experience gap may prove to be (partly) independent of the actual sample size people take. Such a dissociation could occur if people employed decision strategies that use merely part of the actually experienced sample (e.g., due to recency or primacy) or that completely disregard experienced relative frequencies and other proxies for event likelihoods altogether (e.g., the maximax heuristic).

In this paper we will investigate the robustness of and the reasons behind the description-experience gap. To this end, we first aim to replicate the original decisions from experience, using a different sample of participants (Study 1). In Studies 2 and 3, we then examine whether the description-experience gap continues to exist even when people draw on large samples of experience to make a choice. In the final part of the paper, we examine which decision strategies can model decisions from experience and to what extent models that pay no or less heed to experienced relative frequencies may perform better in explaining people's choices than models that take explicit advantage of the experienced frequencies.

\section{STUDY 1. HOW ROBUST IS THE DESCRIPTION-EXPERIENCE GAP?}

As a first step in our investigation, we sought to replicate the description-experience gap as observed by Hertwig et al. (2004). Our motivation for a replication was to establish the robustness both of the humble sampling behavior and the distinct pattern in respondents' decisions from experience, using a larger number of respondents per problem (44 vs. 25 in Hertwig et al.) and drawing on a sample of students whose training in quantitative reasoning and economic concepts (e.g., opportunity costs, see below) is likely to be less sophisticated than that of students in industrial engineering and economics at the Technion.

\section{Method}

\section{Participants}

Two groups of participants made either decisions from experience or decisions from description. The experience group was made up of 44 psychology students from the University of Basel (11 males, 33 females). The mean age was $23.4(S D=6.4)$, with a range from 20 to 40 years. Respondents in the description group participated in a web-based study. To draw on the same pool of student participants in both groups, we excluded all nonstudents from the description group. A total of 110 respondents (45 males, 65 females) remained. Their mean age was 23.2 years ( $S D=3.0$ years), ranging from 19 to 35 years.

\footnotetext{
${ }^{1}$ We conducted the same analysis and arrived at $67 \%$ correct predictions. So far we have not been able to determine the source of the discrepancy but have observed that swapping prospect theory's parameters for the weighting function $(\delta$ and $\gamma)$ yields $69 \%$ performance.
} 


\section{Design and procedure}

The participants responded to the same six choice problems used by Hertwig et al. (2004). They are listed in Table 1. All instructions and stimuli were presented on a computer screen. It was divided in half, one half blue and the other green, representing two decks of cards, each linked to an outcome distribution (henceforth, we use the term deck rather than distribution). People could explore the decks by pressing one of two color-coded buttons on a keyboard, thus eliciting the sampling of an outcome (with replacement). The outcome appeared for 1 second in $200 \mathrm{pt} \mathrm{Verdana} \mathrm{font} \mathrm{over} \mathrm{a} \mathrm{full-screen} \mathrm{background} \mathrm{colored} \mathrm{like} \mathrm{the} \mathrm{selected} \mathrm{deck.} \mathrm{The} \mathrm{initial}$ screen showing both decks then replaced this screen, and the person could sample another outcome. Respondents were instructed to sample until they felt confident enough to decide from which deck to draw for a real payoff. Yet, in 36 of the 264 total trials respondents did not sample from one or even both decks. Judging from our post-experimental interviews, this lack of curiosity was most likely due to the meager financial incentives in this study. We excluded these trials from the analysis.

Participants responded to the problems in a random order. After completing all six problems, participants played out their choices and were paid 0.05 Swiss Francs (approx. US \$0.04) for each point won (e.g., outcome 3 in Problem 1 was equivalent to US \$0.12). We chose a payment scheme as close as possible to that used in the original study, because different incentives can affect people's search behavior and opportunity costs. Note that Hertwig et al. (2004) paid the equivalent of $\$ 0.02$ for each point. We pay 0.05 Swiss Francs because it is the lowest available denomination.

In the description group, respondents saw the same six problems described on a computer screen as the experience group (Table 1) in a random order. For instance, the description of Problem 1 read as follows: " 4 with a chance of $80 \%, 0$ otherwise," and " 3 with a chance of $100 \%$." Participants were told that one of them would be randomly selected, and his or her choices would be played out. For this one participant, each point won was worth CHF 0.50 (approx. US \$0.41) instead of CHF 0.05. We will use the results of this description group as a point of reference in Studies 1-3. In the latter two studies, we will successively make

Table 1. Summary of the decision problems and choice proportions in Study 1

\begin{tabular}{|c|c|c|c|c|c|c|c|}
\hline \multirow[b]{3}{*}{$\begin{array}{l}\text { Decision } \\
\text { problem }\end{array}$} & & & \multirow{2}{*}{$\begin{array}{c}\text { Hertwig et al. } \\
\text { Experience } \\
(n=25)\end{array}$} & \multicolumn{4}{|c|}{ Study 1} \\
\hline & \multicolumn{2}{|c|}{ Options ${ }^{\mathrm{a}}$} & & $\begin{array}{c}\text { Experience } \\
\quad(n=44)\end{array}$ & & & $\begin{array}{c}\text { Description } \\
(n=110)\end{array}$ \\
\hline & Deck H & Deck L & $\begin{array}{l}\text { Choice H } \\
\text { (in \%) }\end{array}$ & $\begin{array}{l}\text { Choice H } \\
\text { (in \%) }\end{array}$ & $\begin{array}{l}\text { Prediction }{ }^{b} \\
\text { for } \mathrm{H} \\
\text { choices }\end{array}$ & Difference $^{c}$ & $\begin{array}{l}\text { Choice H } \\
\text { (in \%) }\end{array}$ \\
\hline 1 & $4,0.8$ & 3,1 & 88 & $62^{\mathrm{d}}$ & Higher & $+29(z=3.79, p=.001)$ & 33 \\
\hline 2 & $\overline{4,0.2}$ & $3,0.25$ & 44 & 55 & Lower & $-27(z=3.23, p=.001)$ & 72 \\
\hline 3 & $-3,1$ & $-32,0.1$ & 28 & 11 & Lower & $-26(z=3.94, p<.001)$ & 37 \\
\hline 4 & $-3,1$ & $-\overline{4,0.8}$ & 56 & 45 & Higher & $+14(z=1.61, p=.108)$ & 31 \\
\hline 5 & $32,0.1$ & 3,1 & 20 & 15 & Lower & $-48(z=6.78, p<.001)$ & 63 \\
\hline 6 & $32,0.025$ & $3,0.25$ & 12 & 28 & Lower & $-19(z=2.30, p=.022)$ & 47 \\
\hline
\end{tabular}

${ }^{a}$ The deck containing a rare event is underlined. $\mathrm{H}$ indicates the deck with the higher expected value, $\mathrm{L}$ the one with the lower expected value. For each deck, only the nonzero outcome is presented along with its probability; the other outcome is 0 with the complementary probability.

${ }^{\mathrm{b}}$ The entries in this column indicate whether the proportion of participants choosing the $\mathrm{H}$ option should be higher or lower in the experience groups (relative to the description group), assuming that rare events have less impact on decisions from experience than on decisions from description.

${ }^{\mathrm{c}}$ This column indicates the percentage of $\mathrm{H}$ choices in the experience group minus the percentage of $\mathrm{H}$ choices in the description group, along with $z$-statistics and $p$-values testing for a difference between these groups (all tests are two tailed).

${ }^{\mathrm{d}}$ This proportion is significantly lower than the proportion observed in the experience group in Hertwig et al. $(z=2.66, p<.008)$. 
changes to the experience group and investigate how these changes alter decisions from experience (relative to the experience and description groups in Study 1).

\section{Results}

Table 1 lists proportions of individuals who chose the higher expected value gamble (see column labeled "Choice H") in the description and experience groups in Study 1. Across all problems, the average (absolute) difference between the percentage of respondents choosing option $\mathrm{H}$ in the description and experience groups was 27 percentage points (36 percentage points in Hertwig et al., 2004). Differences were statistically significant for all problems except for Problem 4. Equally important, the direction of each difference was consistent with that predicted by the assumption that rare events have less impact on decisions from experience than on decisions from description. Table 1 also lists the choice in Hertwig et al.'s experience group. Except for Problem 1, differences between the percentage of respondents choosing option $\mathrm{H}$ in Hertwig et al.'s experience group and Study 1's experience group were small and nonsignificant.

Beyond choice, we also analyzed people's sampling efforts. Our students collected even less information than the Technion students in Hertwig et al. (2004). Figure 1 displays the median number of draws taken for each problem. On average, participants drew a median of 11 total draws per problem (compared to 15 in the original study); the first and third quartiles of total number of observations were 5 and 20, respectively. Replicating another finding in the original study, the average number of draws for both decks was roughly equal.

Respondents' modest sampling effort systematically distorted the probabilities with which they encountered rare events. Across all problems the rare event was not even encountered in $50.3 \%$ of all trials. Moreover, it was sampled less often than implied by its objective probability in an additional $10.5 \%$ of the samples. Finally, the median difference between the experienced relative frequency and the objective probability of the nonzero outcomes was 10.9 percentage points.

To conclude, Study 1 found the same description-experience gap reported by Hertwig et al. (2004). Second, respondents relied on small samples of experience, thus not encountering rare events or encountering

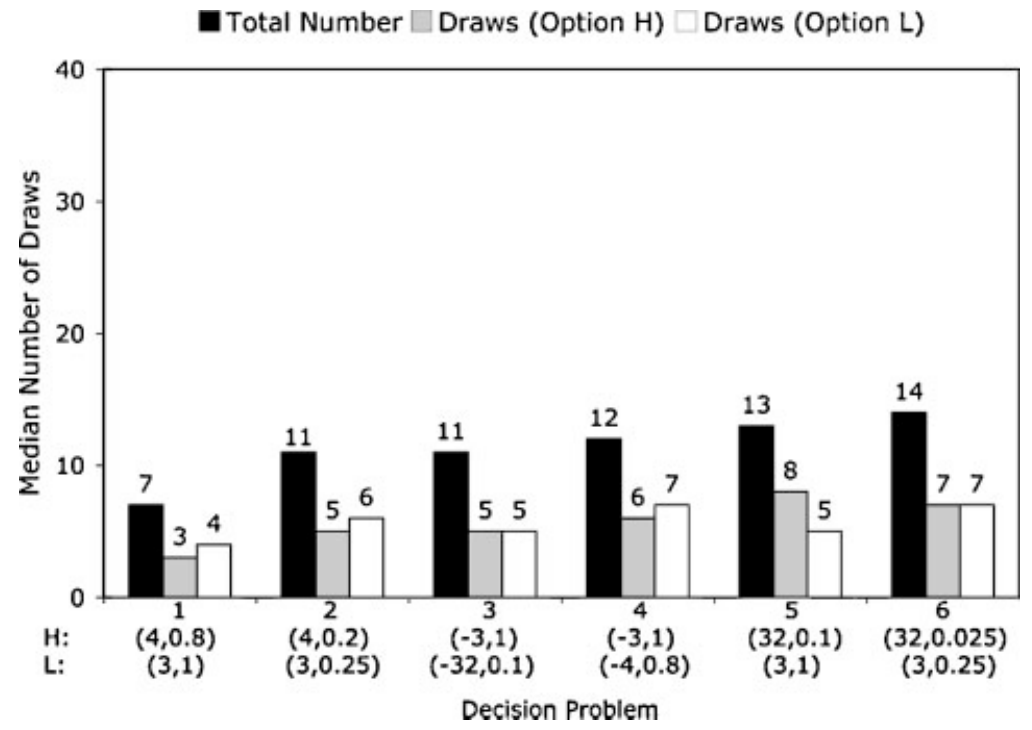

Figure 1. Median number of draws in Study 1 for each of the six decision problems. Results are shown separately for the total number of draws and for draws of the decks with the higher $(\mathrm{H})$ and lower $(\mathrm{L})$ expected values. For each deck, only one outcome is given, followed by its probability; the second outcome, which is not stated, was 0 and occurred with a probability complementary to the stated one. The axis is scaled to allow for easy comparison with Figure 2 
them less frequently than expected according to their objective probability. Third, respondents, on average, sampled roughly equally frequently from both options per problem. We succeeded in replicating the same pattern of decisions from experience that had been previously observed, by using a sample of students quite different from the economics and industrial engineering students investigated in the original study.

\section{STUDY 2. THE DESCRIPTION-EXPERIENCE GAP: DO HIGHER INCENTIVES MAKE IT DISAPPEAR?}

Searching for information takes time-time during which people cannot pursue other activities. In other words, sampling is costly in terms of the things that one has to forgo. Economists refer to this cost as opportunity cost. Taking opportunity costs into account, respondents' reliance on small samples in Study 1 may be perfectly reasonable. To appreciate this point, consider Problem 1 (Table 1). Every draw from the sure-thing deck yields a "3," and a draw from the risky-prospect deck results in either "4" or " 0 ," with the former being four times as likely as the latter (0.8 vs. 0.2). One respondent in our Study 1 sampled four times from the sure-thing deck, each time encountering " 3 ," and sampled three times from the risky-prospect deck, encountering " 0 " once and " 4 " two times. At this point, the mental model of the respondent may have been: a choice between a certain " 3 " versus a 0.67 chance of an outcome " 4 ." The respondent ended up selecting the risky option. The difference between the expected values of " 3 " and " 2.67 " translates into a payoff difference of $1.3 \phi$. In light of the opportunity costs, spending more time exploring these decks may thus indeed be deemed futile (see Harrison, 1989; Smith, 1982, on the precept of payoff dominance; and von Winterfeldt \& Edwards, 1986, for a discussion of flat maxima).

Study 2 investigates three questions related to the costs of information search: First, does increasing the stakes - thus rendering it more expensive not to choose the higher expected value deck-result in more search? Second, more search, if it happens, should lead to information in the experience condition that becomes increasingly, statistically speaking, equivalent to the description condition. But will decisions from experience based on more information simply mirror decisions from description? Third, although sample probabilities will resemble the objective probabilities more closely with more search, how closely will people's beliefs about the likelihood of events track the probabilities experienced in the sample?

\section{Method}

\section{Participants}

A total of 39 students (16 males, 23 females) from the University of Basel participated in the study. Their mean age was 23.8 years $(S D=3.6$ years), ranging from 18 to 33 years.

\section{Design and procedure}

We used the same material and procedure as in the experience group of Study 1, except for two changes. First, we increased the stakes by an order of magnitude: For each respondent, each point won was worth CHF 0.50 (approx. US \$0.41) instead of CHF 0.05. Second, after each problem respondents were asked to report what outcomes they encountered during sampling and to estimate their relative frequency. We will compare people's choices in Study 2 to those made by the description group of Study 1 .

\section{Results}

People search more when stakes are higher. Figure 2 displays the median number of draws per problem. The median number of draws per problem was 33 cards (range: 2-226, interquartile range: 17.5-50), about double 
as many as in Hertwig et al. $(2004$; $m d=15)$ and in Weber et al. $(2004$; md $=17)$. Compared to Study 1 , respondents searched for three times as much information $(\mathrm{md}=11 ; U(230,234)=11300, p<.001)$. As in Study 1 , the average number of draws for deck $\mathrm{H}$ was roughly equal to the number of draws for deck L.

As can be expected from the law of large numbers, the larger samples (relative to Study 1) resulted in more veridical representations of the events' objective probabilities. The median absolute difference between objective and experienced probabilities was 5.0 percentage points (relative to 10.9 percentage points in Study 1). Now, the samples did not contain the rare event in merely $25 \%$ of the trials, compared with $50.3 \%$ in Study 1.

More experience did alter respondents' choices. Table 2 reports the proportion of individuals who chose the $\mathrm{H}$ deck for each problem in the current experience group and the description group of Study 1, respectively. Across all problems, the average (absolute) difference between the percentage of respondents choosing deck $\mathrm{H}$ in the experience and description groups was 13 percentage points (compared to 27 percentage points in Study 1). Now only three of the between-groups differences were statistically significant (Problems 1, 2, and 5). Nevertheless, the direction of each difference was consistent with that predicted by the assumption that rare events have less impact on decisions from experience than on decisions from description. In other words, two to three times as much experience reduces the description-experience gap but does not eliminate it.

Finally, Study 2 renders it possible to examine the degree to which people's estimated probabilities track the actually experienced probabilities. As one possible explanation for the meager impact of rare events in decisions from experience, Fox and Hadar (2006) considered the possibility of a judgment error, according to which people underestimate ("judge") the actually experienced probabilities of rare events. To this end, we considered all trials in which a participant encountered more than one outcome (from a given deck). We eliminated extreme estimates by recursively removing values that were more than three standard deviations off the mean of the absolute difference between the experienced and the estimated probabilities. The resulting average absolute difference for a total of 235 estimates was $M=8.5$ percentage points $(S D=7.3)$, indicating

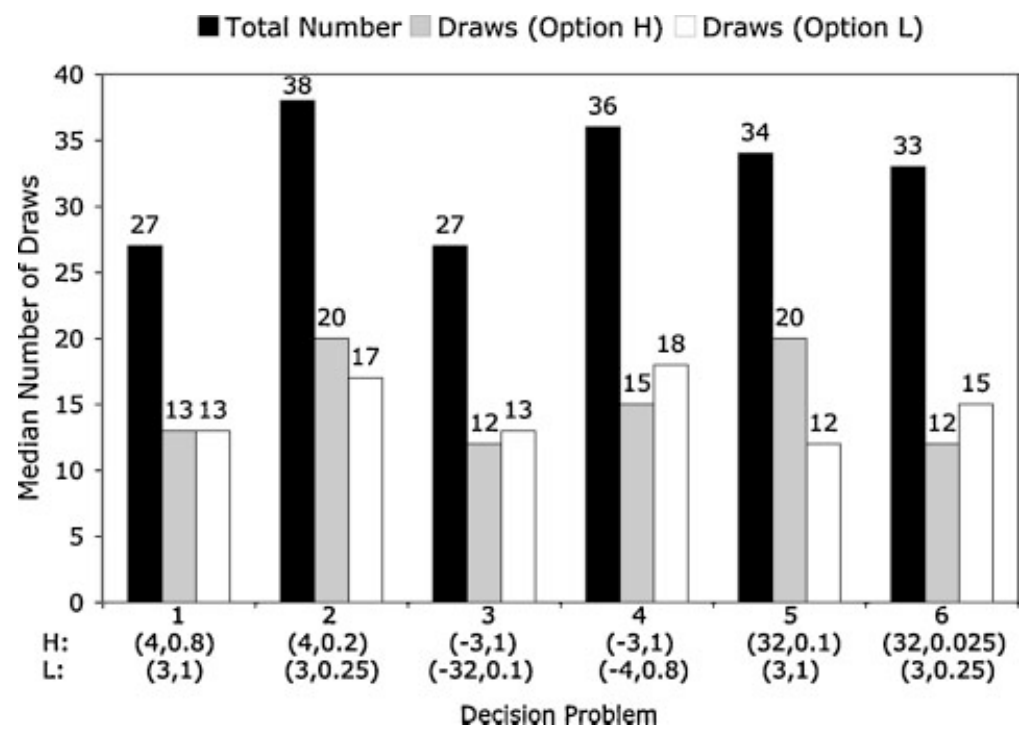

Figure 2. Median number of draws in the experience group of Study 2 for each of the six decision problems (see Table 2). Results are shown separately for the total number of draws and for draws of the decks with the higher (H) and lower (L) expected values. For each deck, only one outcome is given, followed by its probability; the second outcome, which is not stated, was 0 and occurred with a probability complementary to the stated one 
Table 2. Summary of the decision problems and choice proportions in Study 2

\begin{tabular}{|c|c|c|c|c|c|c|}
\hline \multirow[b]{3}{*}{$\begin{array}{l}\text { Decision } \\
\text { problem }\end{array}$} & & & \multicolumn{3}{|c|}{ Study 2} & \multirow{2}{*}{$\begin{array}{c}\text { Study } 1 \\
\begin{array}{c}\text { Description } \\
(n=110)\end{array}\end{array}$} \\
\hline & \multicolumn{2}{|c|}{ Options $^{\mathrm{a}}$} & $\begin{array}{c}\text { Experience } \\
(n=39)\end{array}$ & & & \\
\hline & Deck H & Deck L & Choice $\mathrm{H}$ (in \%) & $\begin{array}{l}\text { Prediction } \\
\text { for } \mathrm{H} \text { choices }\end{array}$ & Difference $^{c}$ & Choice $\mathrm{H}$ (in \%) \\
\hline 1 & $\underline{4,0.8}$ & 3,1 & 56 & Higher & $+23(z=2.52, p=.011)$ & 33 \\
\hline 2 & $\overline{4,0.2}$ & $3,0.25$ & 51 & Lower & $-21(z=2.31, p=.021)$ & 72 \\
\hline 3 & $\overline{-3,1}$ & $-32,0.1$ & 36 & Lower & $-1(z=0.11, p=.911)$ & 37 \\
\hline 4 & $-3,1$ & $-\overline{4,0.8}$ & 36 & Higher & $+5(z=0.56, p=.573)$ & 31 \\
\hline 5 & $32,0.1$ & $\overline{3,1}$ & 36 & Lower & $-27(z=3.01, p=.003)$ & 63 \\
\hline 6 & $32,0.025$ & $3,0.25$ & 46 & Lower & $-1(z=0.11, p=.914)$ & 47 \\
\hline
\end{tabular}

${ }^{a}$ The deck containing a rare event is underlined. $\mathrm{H}$ indicates the deck with the higher expected value, $\mathrm{L}$ the one with the lower expected value. For each deck, only the nonzero outcome is presented along with its probability; the other outcome is 0 with the complementary probability.

${ }^{5}$ The entries in this column indicate whether the proportion of participants choosing the $\mathrm{H}$ option should be higher or lower in the experience groups (relative to the description group), assuming that rare events have less impact on decisions from experience than decisions from description.

${ }^{\mathrm{c}}$ This column indicates the percentage of $\mathrm{H}$ choices in the experience group minus the percentage of $\mathrm{H}$ choices in the description group of Study 1 , along with $z$-statistics and $p$-values testing for a difference between these groups (all tests are two tailed).

that people's estimates were clearly not perfectly aligned with the probabilities. Echoing a finding obtained in many other studies (see Gottlieb, Weiss, \& Chapman, 2007; Hertwig, Pachur, \& Kurzenhäuser, 2005), we also observed slight overestimation of small and underestimation of large probabilities. The regression line in Figure $3 \mathrm{a}$, predicting the estimated frequencies from the experienced frequency, shows this phenomenon, typically interpreted as a consequence of regression toward the mean (Hertwig et al., 2005). In other words, to the extent that there is a judgment error (Fox \& Hadar), it should foster rather than diminish the impact of rare events.

To conclude, Study 2 yielded three insights into the description-experience gap. Increasing financial stakes increased search. Compared to Study 1, respondents sampled three times as much. In addition, more search reduced the difference in choices between the experience and the description groups, but did not eliminate it. This finding confirms sampling error due to small samples as a key reason for the disparity between both types of decisions, consistent with Fox and Hadar (2006) and Hertwig et al. (2004). Finally, we also found that the amount of experience our respondents sought did not yield completely accurate beliefs about the events' objective probabilities: The estimated probabilities were such that rare events were overestimated. In light of this slight overestimation the remaining description-experience gap-consistent with the assumption that rare events in decisions from experience have less impact than in decisions from description-is notable.

\section{STUDY 3. THE DESCRIPTION-EXPERIENCE GAP: DOES EXTENSIVE SEARCH MAKE IT DISAPPEAR?}

Although people sampled more information in Study 2, relative to Study 1, there was still a total of $25 \%$ of trials in which the rare event was not encountered. If this number were further reduced, would the description-experience gap shrink further and eventually disappear? Study 3 was designed to investigate this 
(a) Study 2

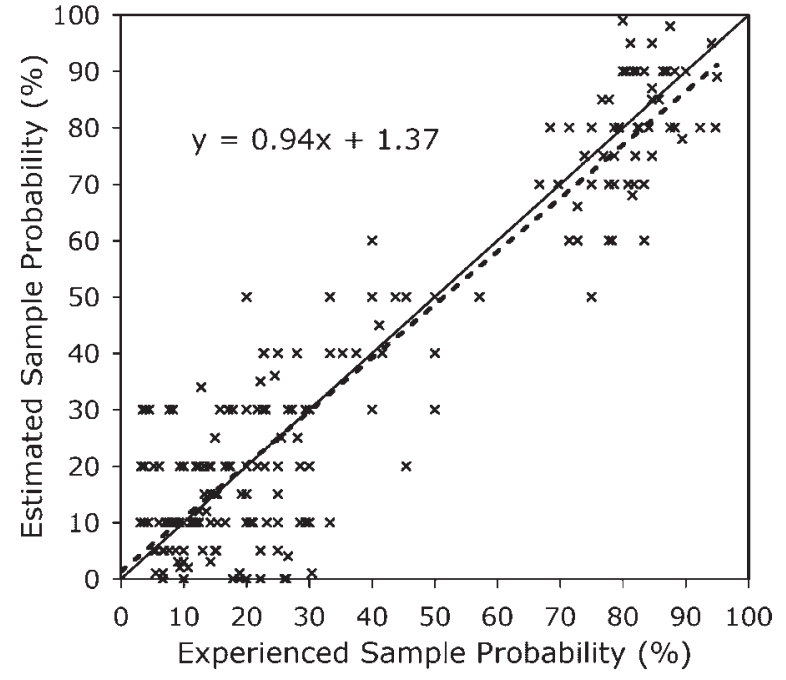

(b) Study 3

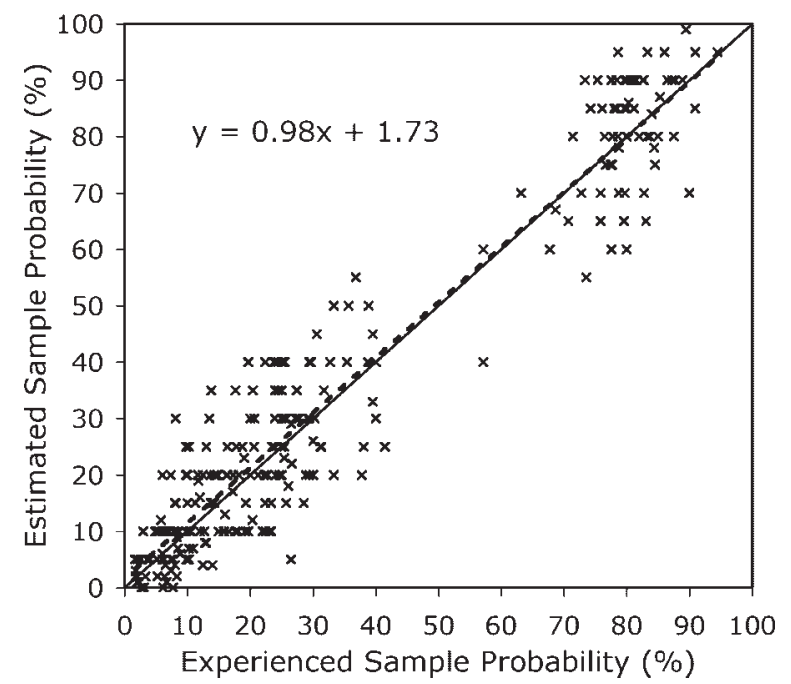

Figure 3. Scatterplot of experienced sample probabilities and participants' corresponding estimates for Studies 2 (Panel a) and 3 (Panel b). Every point represents the probability with which a person experienced an outcome and his or her respective estimate. Optimal calibration is indicated by the diagonal. The dashed lines mark the least-square regression

lines for Studies 2 and 3, separately. Outliers were removed from the data before fitting the regression lines

possibility: Specifically, respondents were required to sample a total of 100 times before they could render their final choice.

\section{Method}

\section{Participants}

Forty students from the University of Basel participated (15 males, 25 females). Their mean age was 24 years $(S D=4.1$ years), with a range from 19 to 38 years. 


\section{Design and procedure}

We used the same material and procedure as in the experience group of Study 2, except that the sampling phase was not terminated by the participants but ended after they had sampled a total of 100 cards from both decks combined. Respondents were informed that the program would require them to sample 100 times. Otherwise, they could sample in whatever order they preferred and could distribute their 100 draws between decks as they saw fit. After each choice, they were asked to estimate the probability with which the various outcomes occurred in the sample. They received the same monetary payment as in Study 2. Again, we will compare the results to the decisions from description observed in Study 1.

\section{Results}

Sampling 100 times provided respondents with quite accurate experiences of the outcomes' objective probabilities. Specifically, the median absolute difference between objective and experienced probabilities was 3.3 percentage points (compared with 10.9 and 5.0 percentage points in Studies 1 and 2, respectively). Moreover, respondents encountered the rare event at least once in all but $10 \%$ of their samples (compared to 50.3 and $25 \%$ in Studies 1 and 2, respectively).

Does this substantially larger sample render the description-experience gap smaller than in Study 2 ? Table 3 lists the proportions of choices of deck $\mathrm{H}$ across problems. The gap did not close. Across all problems, the average (absolute) difference between the percentage of respondents choosing deck H in Study 3 and the description group in Study 1 was 17 percentage points (compared to 13 percentage points in Study 2). Again, three of the between-groups differences were statistically significant (Problems 1, 4, and 5). The direction of each difference was consistent with that predicted by the assumption that rare events have less impact on decisions from experience than on decisions from description for all problems except Problem 2. If one subtracts the Problem 2 difference from the sum of all absolute differences and then calculates the average difference, the gap between the experience group (Study 3) and the description group (Study 1) is still 15 percentage points. In other words, tripling the size of the experience sample, relative to Study 2, does not appear to further reduce the description-experience gap.

Table 3. Summary of the decision problems and choice proportions in Study 3

\begin{tabular}{|c|c|c|c|c|c|c|}
\hline \multirow[b]{3}{*}{$\begin{array}{l}\text { Decision } \\
\text { problem }\end{array}$} & \multicolumn{4}{|c|}{ Study 3} & & \multirow{2}{*}{$\frac{\text { Study } 1}{\text { Description }(n=110)}$} \\
\hline & Opti & ons $^{\mathrm{a}}$ & Experience $(n=40)$ & & & \\
\hline & Deck H & Deck L & $\begin{array}{l}\text { Choice H } \\
\text { (in \%) }\end{array}$ & $\begin{array}{l}\text { Prediction } \\
\text { for } \mathrm{H} \text { choices }\end{array}$ & Difference $^{c}$ & $\begin{array}{l}\text { Choice } \mathrm{H} \\
\text { (in \%) }\end{array}$ \\
\hline 1 & $4,0.8$ & 3,1 & 65 & Higher & $+32(z=3.64, p=.000)$ & 33 \\
\hline 2 & $\overline{4,0.2}$ & $3,0.25$ & 78 & Lower & $+6(z=0.77, p=.443)$ & 72 \\
\hline 3 & $\overline{-3,1}$ & $-32,0.1$ & 30 & Lower & $-7(z=0.82, p=.415)$ & 37 \\
\hline 4 & $-3,1$ & $\overline{-4,0.8}$ & 55 & Higher & $+24(z=2.66, p=.008)$ & 31 \\
\hline 5 & $32,0.1$ & $\overline{3,1}$ & 40 & Lower & $-23(z=2.55, p=.011)$ & 63 \\
\hline 6 & $3 \overline{2,0.025}$ & $3,0.25$ & 38 & Lower & $-9(z=1.00, p=.319)$ & 47 \\
\hline
\end{tabular}

${ }^{a}$ The deck containing a rare event is underlined. $\mathrm{H}$ indicates the deck with the higher expected value, $\mathrm{L}$ the one with the lower expected value. For each deck, only the nonzero outcome is presented along with its probability; the other outcome is 0 with the complementary probability.

${ }^{\mathrm{b}}$ The entries in this column indicate whether the proportion of participants choosing the $\mathrm{H}$ option should be higher or lower in the experience groups (relative to the description group), assuming that rare events have less impact on decisions from experience than on decisions from description.

${ }^{\mathrm{c}}$ This column indicates the percentage of $\mathrm{H}$ choices in the experience group minus the percentage of $\mathrm{H}$ choices in the description group of Study 1 , along with $z$-statistics and $p$-values testing for a difference between these groups (all tests are two tailed). 
Using the same procedures as in Study 2, we analyzed people's estimates of the outcomes' probabilities in the sample of 100 draws. The average absolute difference in a total of 286 estimates was $M=6.6$ percentage points $(S D=5.2)$. Again, we observed a slight overestimation of small sample probabilities and underestimation of large sample probabilities. By comparing the two regression lines in Figure $3 \mathrm{a}$ and Figure $3 \mathrm{~b}$, one can infer that this pattern of over- and underestimation was less pronounced than in Study 2. If one further increased the sample size from 100 to, say, 500 draws, the pattern of over- and underestimation would likely be even further reduced, and, perhaps, eliminated. Yet, the results in Study 3, relative to those in Study 2, suggest that such extensive samples will not further diminish the description-experience gap.

\section{THE DESCRIPTION-EXPERIENCE GAP ACROSS STUDIES 1-3}

What have we learned about the description-experience gap from these three studies? More experience reduces the gap but does not make it disappear. Figure 4 corroborates this conclusion. Assuming that the rare event in a problem favors a deck in which it is included (if the rare event is desirable) or the opposite deck (if the rare event is undesirable), we calculated, collapsing across problems in each study, the average proportion with which the favored deck was selected in decisions from experience (Studies 1-3) and decisions from description (Study 1). In Study 1's decision from description group the option favored by the rare event was chosen in 59\% of cases, relative to 34,46 , and $44 \%$ in experience groups of Studies $1-3$. All description-experience gaps are statistically significant.

\section{WHICH MODEL ACCOUNTS BEST FOR DECISIONS FROM EXPERIENCE?}

In the final part of the paper, we examine which decision strategies can predict decisions from experience and to what extent models that pay no or less heed to experienced sample probabilities may perform better than models that take explicit advantage of the experienced probabilities. If, for instance, a strategy that uses solely outcome information and ignores probabilities altogether proves to be a good model of decisions from experience, this could explain why the description-experience gap persists even in light of more sampled experience. The candidate models can be separated into two categories: associative-learning models and models of heuristics. In addition, our model comparison will include the two-stage model of cumulative

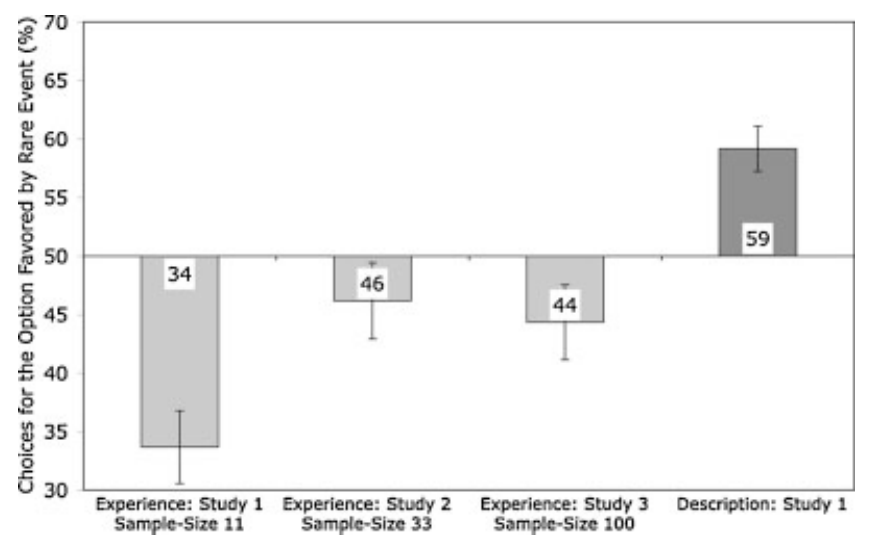

Figure 4. The description-experience gap and the median number of draws in the respective experience groups. The bars indicate the average percentage of choices for the option favored by the rare event. Error bars indicate \pm one standard error 
prospect theory as a model for decisions from experience (as suggested by Fox \& Hadar, 2006). In what follows, we briefly describe the contestants.

\section{Two-stage model of cumulative prospect theory}

The two-stage model assumes that people first form subjective beliefs of the probability of events, and then enter these beliefs into cumulative prospect theory's weighting function (Fox \& Tversky, 1998; Tversky \& Fox, 1995). A descriptive alternative to expected utility theory, cumulative prospect theory was developed as a model of how people make decisions from description (Kahneman \& Tversky, 1979; Tversky \& Kahneman, 1992). Applied to decisions from experience (here, two-outcome gambles), the two-stage model of cumulative prospect theory (for brevity, we will henceforth refer only to the two-stage model) consists of three steps.

Step 1. Assess the sample probability, that is, the relative frequency, $p_{i}$, of the nonzero outcome in deck $j^{2}$

Step 2. Calculate the expected gain (loss) of $\operatorname{deck} j, E_{j}$,

$$
E_{j}=w\left(p_{j}\right) v\left(x_{j}\right)
$$

where $w$ represents a weighting function for the probabilities experienced in the sample, and $v$ represents a value function for the experienced outcomes. According to Tversky and Kahneman (1992), the weighting function $w$ is:

$w\left(p_{j}\right)= \begin{cases}\frac{p_{j}^{\gamma}}{\left(p_{j}^{\gamma}+\left(1-p_{j}\right)^{\gamma}\right)^{1 / \gamma}}, & \text { if } x \geq 0 \\ \frac{p_{j}^{\delta}}{\left(p_{j}^{\delta}+\left(1-p_{j}\right)^{\delta}\right)^{1 / \delta}}, & \text { if } x<0\end{cases}$

The $\gamma$ and $\delta$ are adjustable parameters that fit the shape of the function for gains and losses, respectively. Both parameters are typically assumed to range between 0 and 1, resulting in an inverse S-shape that overweights small probabilities and underweights large ones. The value function $v$ is:

$v\left(x_{j}\right)= \begin{cases}x_{j}^{\alpha}, & \text { if } x_{j} \geq 0 \\ -\lambda\left(\left|x_{j}\right|^{\beta}\right), & \text { if } x_{j}<0\end{cases}$

The $\alpha$ and $\beta$ are adjustable parameters that fit the curvature for the gain and loss domain, respectively. Finally, the $\lambda$ parameter $(\lambda>1)$ scales loss aversion.

Step 3. Choose the most attractive deck.

Equations (1) and (2) include five adjustable parameters, but $\lambda$ has no bearing on nonmixed gambles and is therefore irrelevant to our analysis. Following Fox and Hadar (2006), we use the median estimates of Tversky and Kahneman (1992) to predict choices $(\alpha=\beta=0.88, \gamma=0.61, \delta=0.69)$. These values imply overweighting of small probabilities, underweighting of large probabilities, and diminishing sensitivity to gains and losses. One serious objection to using these values in the current context is that they were derived from

\footnotetext{
${ }^{2}$ Note that the two-stage model would use people's estimates of the sample probabilities. Like Fox and Hadar (2006) in their reanalysis of Hertwig et al.'s (2004) data, we used people's actually experienced sample probabilities instead, thus avoiding the introduction of additional noise into the modeling. However, we also conducted the same analysis with people's estimated probabilities from Studies 2 and 3. As a consequence, the predictive performance of the two-stage model decreased in Study 2 (by 7 percentage points) and increased (by 3 percentage points) in Study 3, respectively. Averaged across both studies, the model's performance was thus better with the actually experienced than with the estimated probabilities.
} 
decisions from description, thus they may not be appropriate for modeling decisions from experience. To address this objection, we also fit the four parameters to Hertwig et al.'s (2004) data thus generating a set of parameters specific for decisions from experience (for details see below).

\section{Associative-learning models}

On a very different view, human choice is not conceptualized as a calculated (Bernoullian or Neo-Bernoullian) expected utility, but as a response gauged from experience. This process is modeled with associative-learning models (see, e.g., Busemeyer \& Myung, 1992; Bush \& Mosteller, 1955; Estes, 1959) according to which favorable experiences boost the propensity of choosing the deck associated with them; by extension, unfavorable experiences diminish that propensity (e.g., Barron \& Erev, 2003; Denrell, 2007; Erev \& Barron, 2005; March, 1996). We investigate two experiential-learning models, the value-updating model and the fractional-adjustment model.

Value-updating model. Hertwig et al. (2006) developed the value-updating model to account for the results of Hertwig et al. (2004). It assumes that learners update their estimates of the value of an alternative after each new draw from that deck by computing a weighted average of the previously estimated value and the value of the most recently experienced outcome. The model consists of two steps:

Step 1. Set your initial expectation about the values $A_{j}(0)$ of deck $j$ to zero. After the th draw from that deck update the value of that deck according to the following term:

$$
A_{j}(t)=\left(1-\omega_{t}\right) A_{j}(t-1)+\left(\omega_{t}\right)\left(x_{t}\right)
$$

where $A_{j}(t)$ represents the value of the deck $j$ after $t$ samples are drawn. The weight accorded to the new outcome is $\omega=(1 / t)^{\varphi}$, where $\varphi$ is a recency parameter. If $\varphi=1$, all outcomes are equally weighted; if $\varphi<1$, more recent outcomes receive more weight, implying a recency effect, and if $\varphi>1$, earlier outcomes receive more weight, implying a primacy effect. ${ }^{3}$

Step 2. Once sampling is terminated, select the deck with the highest value.

The structure of the model is such that the value, $A_{j}(t)$, represents a weighted average of (a) the value of the deck, based on the $t-1$ previously sampled outcomes, $A_{j}(t-1)$, and (b) the value of the most recent outcome, $x_{t}$. The sample sizes are empirically determined, whereas the recency parameter is fitted to the Hertwig et al. (2004) data. The input to the value-updating model is whatever sample size and sample sequence a respondent chose to experience.

Fractional-adjustment model. As a second associative-learning model, we include March's (1996) fractional-adjustment model that Weber et al. (2004) used to describe the learning process in decisions from experience observed in their study. The model consists of two steps.

Step 1. Set the initial propensity $p_{j, 0}$ to choose each deck to 0.5 . Increment the propensity of choosing deck $j$ after sampling trial $t$ according to the observation of the payoff, $x_{j}$, using the following rule:

$$
p_{j, t}= \begin{cases}1-\left[(1-\alpha)^{x_{j}}\left(1-p_{j, t-1}\right)\right] & \text { if } x_{j} \geq 0 \\ p_{j, t-1}(1-\alpha)^{x_{j}} & \text { if } x_{j}<0\end{cases}
$$

\footnotetext{
${ }^{3}$ Hertwig et al. (2006) assumed that the experienced values are transformed using cumulative prospect theory's value function (see Equation 2). Since the predictive performance of the value-updating model proved to be nearly identical with and without these additional parameters in all our analyses, we removed them from Equation 3.
} 
Table 4. Outcome heuristics applied to decisions from experience

\begin{tabular}{ll}
\hline Heuristic & Choice policy steps \\
\hline Equiprobable & Step 1: Calculate the arithmetic mean of all experienced outcomes within a deck \\
Step 2: Choose the deck with the higher mean \\
Example choice: Equiprobable chooses B, because B has a higher mean (16) than A (3) \\
Step 1: Calculate the sum of all experienced outcomes within a deck \\
Step 2: Choose the deck with the higher sum \\
Example choice: Equal weight chooses B, because B has a higher sum (32) than A (3) \\
Step 1: Choose the deck with largest experienced minimum outcome \\
Example choice: Minimax chooses A, because B has a lower minimum outcome (0) \\
than A (3) \\
Step 1: Choose the deck with the higher experienced maximum outcome \\
Exinimax \\
Example choice: Maximax chooses B, because its maximum outcome (32) is higher \\
than A's (3) \\
Step 1: Calculate the grand average of all experienced outcomes from all decks \\
Step 2: For each deck, count the number of outcomes equal to or above the grand \\
average \\
Step 3: Choose the deck with the highest number of such outcomes \\
Example choice: The grand average equals 11.66 (32+3 $0 / 3)$ The better than average \\
heuristic chooses deck B, because only deck B has one outcome above this threshold
\end{tabular}

Notes: The prediction for each heuristic refers to the choice between decks $\mathrm{A}$ and $\mathrm{B}$, respectively, given a person experienced sequence 3 , $3,3,3,3,3,3,3,3,3$ from deck A, and sequence $0,0,0,0,0,0,32,0,0,0$ from deck B. Note that the term outcome, as used in the table, does not refer to each single event experienced but to a class of identical events. For instance, the sample from deck B includes the occurrence of two outcomes, "0" and "32;" the latter occurred once, the former nine times in the sample.

Parameter $\alpha$ is adjustable and controls the degree of learning. It is bound between 0 and 1 . If $\alpha=0$, then there will be no learning.

Step 2. Choose the deck with the larger propensity. ${ }^{4}$

As with the parameters of the previous two models, the learning parameter $\alpha$ will be fitted to the Hertwig et al. (2004) data.

\section{Outcome and dual heuristics}

Heuristics can be separated into two classes: those that use solely outcome information and ignore probabilities (outcome heuristics), and those that use at least rudimentary probability information (dual heuristics). Outcome heuristics such as maximax and minimax (see Luce \& Raiffa, 1957) were originally proposed as models for decisions under ignorance in which people have no information about probabilities. In decisions from experience, people initially have no probability information, and if search is terminated early it is only modestly reliable. Therefore, heuristics that use either no probability information or merely rudimentary probability information may be good candidates for decisions from experience.

In our analysis, we include most of the classic heuristics simulated by Thorngate (1980), the lexicographic and the equal-weight heuristics (Dawes, 1979) from Payne, Bettman, and Johnson (1993), and the tallying heuristic and the priority heuristic (Brandstätter, Hertwig, \& Gigerenzer, 2006). The heuristics are described in Tables 4 and 5, in which their algorithm is explained using the following sampling experience (from two

\footnotetext{
${ }^{4}$ The original choice rule was stochastic where the person chose the deck with a probability consistent with the propensity. We have modified this rule to make choice deterministic and consistent with all the other models described here.
} 
Table 5. Dual heuristics applied to decisions from experience

\begin{tabular}{|c|c|}
\hline Heuristic & Choice policy steps \\
\hline Tallying & $\begin{array}{l}\text { Step 1: Give a tally mark to the deck with (a) the higher minimum gain, (b) the higher } \\
\text { maximum gain, (c) the lower experienced frequency of the minimum gain, } \\
\text { and (d) the higher experienced frequency of the maximum gain. For losses, } \\
\text { replace "gain" by "loss" and "higher" by "lower" (and vice versa) } \\
\text { Step 2: Choose the deck with the higher number of tally marks } \\
\text { Example choice: Tallying guesses, because both deck A (one tally mark for the higher } \\
\text { minimum outcome, one for the higher frequency of the maximum outcome) and deck B } \\
\text { (one tally mark for the lower frequency of the minimum outcome, one for the higher } \\
\text { maximum outcome) receive two tally marks each }\end{array}$ \\
\hline Most likely & $\begin{array}{l}\text { Step 1: Determine the most frequently experienced outcome of each deck } \\
\text { Step 2: Choose the deck with the highest (most frequent) outcome } \\
\text { Example choice: Most likely chooses A, because deck A's most frequent } \\
\text { outcome exceeds that of deck B ( } 3 \text { vs. } 0)\end{array}$ \\
\hline Lexicographic & $\begin{array}{l}\text { Step 1: Determine the most frequently experienced outcome of each deck } \\
\text { Step } 2 a \text { : Choose the deck with the highest most frequent outcome } \\
\text { Step } 2 b \text { : If both are equal, determine the second most frequent outcome of each deck, } \\
\text { and select the deck with the highest (second most frequent) outcome. } \\
\text { Proceed until a decision is reached } \\
\text { Example choice: Lexicographic chooses A, because deck A's most frequent outcome } \\
\text { exceeds that of deck B ( } 3 \text { vs. } 0)\end{array}$ \\
\hline Least likely & $\begin{array}{l}\text { Step 1: Determine the worst experienced outcome for each deck } \\
\text { Step 2: Choose the deck with the lowest sample probability of the worst payoff } \\
\text { Example choice: Least likely chooses B, because deck B's worst outcome }(0 ; 90 \%) \text { was less } \\
\text { frequent than deck A's worst outcome }(3 ; 100 \%)\end{array}$ \\
\hline Probable & $\begin{array}{l}\text { Step 1: Categorize experienced outcomes as probable (i.e., experienced at least } 50 \% \text { of the time) } \\
\text { or improbable } \\
\text { Step 2: Cancel improbable outcomes } \\
\text { Step 3: Calculate the arithmetic mean of the probable outcomes for each deck } \\
\text { Step 4: Choose the deck with the highest average payoff } \\
\text { Example choice: Probable chooses A, because its probable outcome (3) is more attractive } \\
\text { than deck B's probable outcome (0) }\end{array}$ \\
\hline Priority & $\begin{array}{l}\text { Step 1: Examine the minimum gains experienced in the samples of outcomes from decks } \\
\text { A and B, respectively. If they differ by } 1 / 10 \text { (or more) of the maximum gain } \\
\text { experienced (in both samples), stop examination and choose the deck distribution } \\
\text { with the more attractive minimum gain; otherwise go to Step } 2 \\
\text { Step 2: Examine the sample probabilities of the minimum gains. If the probabilities differ } \\
\text { by } 1 / 10 \text { (or more) of the probability scale, stop examination and choose the deck } \\
\text { distribution with the more attractive probability; otherwise go to Step } 3 \\
\text { Step 3: Examine the maximum gain experienced in each deck distribution. } \\
\text { Choose the deck distribution with the more attractive gain }{ }^{\text {a }} \\
\text { Example choice: Priority heuristic chooses B, because the sample probability of } \\
\text { deck A's minimum outcome is } 10 \text { percentage points larger than that of deck B's minimum } \\
\text { outcome (Step 2) }\end{array}$ \\
\hline
\end{tabular}

Notes: The prediction for each heuristic refers to the choice between decks A and B, respectively, given a person experienced sequence 3 , $3,3,3,3,3,3,3,3,3$ from deck A, and sequence 0, 0, 0, 0, 0, 0, 32, 0, 0, 0 from deck B. Note that the term "outcome," as used in the table, does not refer to each single event experienced but to a class of identical events. For instance, the sample from deck B includes the occurrence of two outcomes, " 0 " and "32;" the latter occurred once, the former nine times in the sample.

${ }^{a}$ In case a participant experiences only a single outcome in a distribution (either because it involves only a single outcome or because the participant has terminated search before another outcome occurred), the experienced outcome is simultaneously the maximum and the minimum gains. When applied to negative outcomes, the heuristic is identical except that "gains" are replaced by "losses." 
decks, A and B):

$$
\begin{aligned}
& \text { Sequence } A: \quad 3,3,3,3,3,3,3,3,3,3 \\
& \text { Sequence } B: \quad 0,0,0,0,0,0,32,0,0,0
\end{aligned}
$$

The decks represent the following lotteries (we chose the sequences so that the frequencies of the outcomes exactly matched their objective probabilities):

$$
\begin{array}{ll}
A: & 3 \text { for sure. } \\
B: & 10 \% \text { chance to win } 32 \\
& 90 \% \text { chance to win } 0
\end{array}
$$

In addition, we include a heuristic, the natural-mean heuristic (Hertwig \& Pleskac, 2008) that, unlike some of the other heuristics, is tailored to the sequentially encountered outcome information unique to decisions from experience. This heuristic cannot be applied to decisions from description. The natural-mean heuristic was originally proposed in the context of $n$-armed bandit problems (Sutton \& Barto, 1998) as a simple method for estimating the values of actions (e.g., the play of one of a slot machine's levers), and for using the estimates to make action selection decisions. ${ }^{5}$ According to Sutton and Barto, "the true value of an action is the mean reward received when the action is selected. One natural way to estimate this is by averaging the rewards actually received when the action was selected" (p. 27). The natural-mean heuristic consists of two steps:

Step 1. Calculate the natural mean of experienced observations in both decks by summing, separately for each deck, all $n$ experienced outcomes and then dividing by $n$.

Step 2. Choose the deck with the larger natural mean (i.e., the deck that had the best average outcome in the sampling phase).

The natural-mean heuristic has several interesting characteristics. For one the natural-mean heuristic makes the same outcome or choice predictions as the expected-value calculus applied to sampled probabilities and outcomes. However, the heuristic arrives at a choice through a different process. Rather than keeping track of all outcomes and their respective probabilities, multiplying each by the other and summing up, the heuristic tots up all experienced rewards (or losses) per deck and then divides this sum by the sample size per deck to yield the "natural mean." When a person draws samples of equal size — which about one-fifth to one-third of people did in Studies 1-3-the heuristic requires merely summing across all outcomes from a deck. One interpretation of the natural-mean heuristic is that it is a simple and psychologically feasible (in particular in continuous outcome distributions) instantiation of expected value. Because of the natural-mean's relation to expected value this also means that at the outcome level the heuristic is mathematically nested within Fox and Tversky's (1998) two-stage model and Hertwig et al.'s (2006) value-updating model. In fact, if the adjustable parameters within the latter two models are fixed to be 1 , then all three models will make identical predictions.

\section{Fitting the models to existing data}

Some of the strategies in our analysis are parametric models. In order to avoid the problem of overfitting, we employ the generalization approach (Busemeyer \& Wang, 2000). That is, for each model with adjustable parameters we found the optimal set of parameters for the aggregate choices in the experience group in Hertwig et al. (2004), using the number of correct predictions as an optimization criterion. On the basis of the resulting parameter values, we predicted choices in Studies 1-3. A benefit of this generalization method is

\footnotetext{
${ }^{5}$ Note that, unlike in $n$-armed bandit problems, in decisions from experience, as studied here, the outcomes in the sampling stage represent hypothetical but not actual rewards. That is, sampling is exogenous (Denrell, 2007).
} 


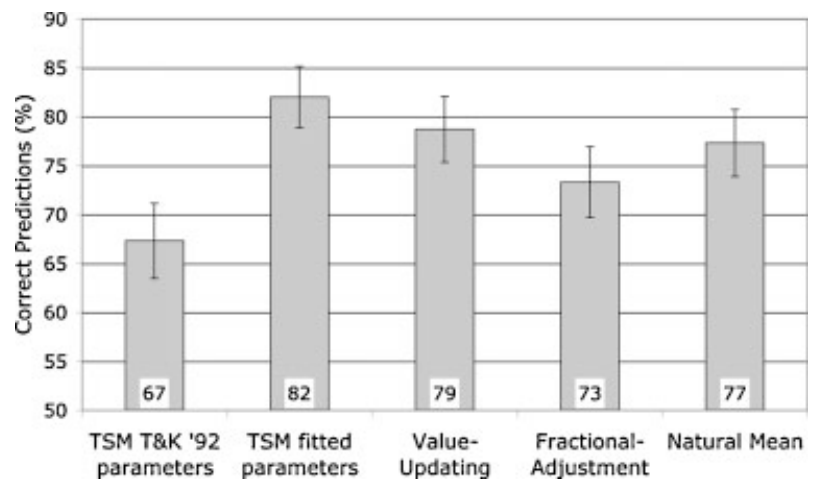

Figure 5. Model performance for Hertwig et al.'s (2004) decisions from experience data. For comparison, the two-stage model (TSM) with parameters estimated by Tversky and Kahneman (1992) for decisions from description and the natural-mean heuristic, are included. Error bars indicate \pm one standard error

that in a new data set, it puts models with adjustable parameters on equal footing with models without adjustable parameters. Thus, this procedure accounts for both goodness-of-fit as well as model complexity.

To fit the two-stage model and the two associative-learning models, we varied all the adjustable parameters in steps of 0.01 between 0 and 1 and calculated the number of correct "predictions" for each value or combination of values. The set of parameters that produced the maximum number of correct choice predictions was selected as the parameter estimate. ${ }^{6}$ Figure 5 displays the performance of the models when fitted to Hertwig et al.'s (2004) decisions from experience, relative to the performance of the natural-mean heuristic and the two-stage model using the parameters estimated by Tversky and Kahneman (1992). Table 6 reports the fitted parameters for all models. As Figure 5 shows, Tversky and Kahneman's (1992) parameter values are not well suited to fit Hertwig et al.'s decisions from experience data. By fitting parameters, the performance can be increased to $82 \%$, relative to $67 \%$. The optimized parameters for the two-stage model, in particular the weighting function parameters, are very close to unity (Table 6) - an issue to which we return in the discussion. Moreover, Figure 5 shows that even with optimal parameters, the two-stage model and the value-updating model perform only slightly better than the natural-mean heuristic (which is nested within both models). Finally, the fractional-adjustment model performs worse than the other fitted models and the natural-mean heuristic, respectively.

\section{PREDICTING DECISIONS FROM EXPERIENCE}

How well do the models predict decisions from experience in Studies 1-3? To find out, we pooled the 732 individual choices in these studies, and predicted them based on the individual sampling sequences, separately for the heuristics, the associative-learning models, and the two-stage model. Figure 6 plots the predictive performance of all candidate strategies.

With $69 \%$ correct predictions, the two best-performing strategies were the maximax heuristic and the two-stage model with parameters fitted to decisions from experience. Clearly, the top performing models are close. Comparing all strategies with the performance of the best ones using two-sided $z$-tests, we found that a

\footnotetext{
${ }^{6}$ Owing to the discrete nature of the criterion "correct predictions," maxima of optimal parameters are truly flat in the sense that several parameter values make the exact same number of correct predictions. Therefore, we chose from the optimal values the one that is closest to the mean of all optimal values.
} 
Table 6. Optimal parameters fit to the data of Hertwig et al. (2004)

\begin{tabular}{|c|c|c|}
\hline Model & Optimal parameters & Implication \\
\hline Two-stage model & $\alpha=.94, \beta=.86, \gamma=.99, \delta=.93$ & $\begin{array}{l}\text { Diminishing returns for gains and losses, } \\
\text { more pronounced for losses; nearly } \\
\text { linear weighting of probabilities }\end{array}$ \\
\hline Value-updating model & $\varphi=.75$ & Substantial recency effect \\
\hline Fractional-adjustment model & $\alpha=.05$ & Slow change of choice propensity \\
\hline
\end{tabular}

Notes: Parameters were varied in steps of .01 to maximize correct choice predictions; where several parameter values performed equally well, we chose those values that were closest to the mean of all optimal values.

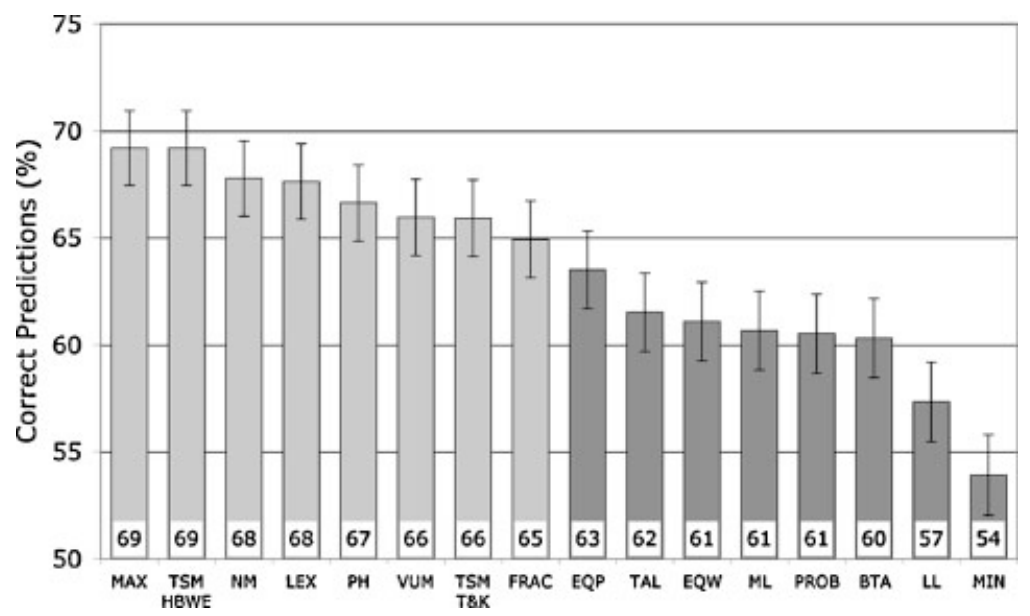

Figure 6. Predictive performance of the models across decisions from experience obtained in Studies 1-3. The models, sorted by performance, are: MAX, maximax; TSM HBWE, two-stage model with parameters fitted to the Hertwig et al. (2004) data; NM, natural mean; LEX, lexicographic; PH, priority heuristic; VUM, value-updating model; TSM T\&K, two-stage model with the Tversky and Kahneman (1992) parameter; FRAC, fractional-adjustment model; EQP, equiprobable; TAL, tallying; EQW, equal weight; ML, most likely; PROB, probable; BTA, better than average; LL, least likely; MIN, minimax. The strategies represented by dark gray bars performed significantly $(z$-test, $p<.05)$ worse than the two best strategies. For a description of the heuristics, see Tables 4 and 5 . Error bars indicate \pm one standard error

total of six strategies did not predict reliably worse than the best two strategies. These are the natural-mean heuristic ( $68 \%$ correct, $z=0.57, p=.57$ ), the lexicographic heuristic (68\% correct, $z=0.63, p=.53)$, the priority heuristic $(67 \%$ correct, $z=1.03, p=.30)$, and the value-updating model (66\% correct, $z=1.30$, $p=.20)$, the two-stage model ( $66 \%$ correct, $z=1.31, p=.19)$ with the median parameters of Tversky and Kahneman (1992; 66\% correct, $z=1.31, p=.19)$, and the fractional-adjustment model $(65 \%$ correct, $z=1.70, p=.09)$.

In light of this "tight race," what can we learn from such an analysis? First, an outcome heuristic that takes no probabilities into account, the maximax heuristic, appears to be a candidate strategy for decisions from experience. In light of a recent extensive analysis of decisions from description this performance is remarkable: in that investigation the maximax heuristic performed dismally (see Brandstätter et al., 2006; Figure 7). Second, the top contenders reliably outperform a number of heuristics, namely, all strategies to the right of the fractional-adjustment model in Figure 6. In contrast, three heuristics, maximax, the lexicographic 


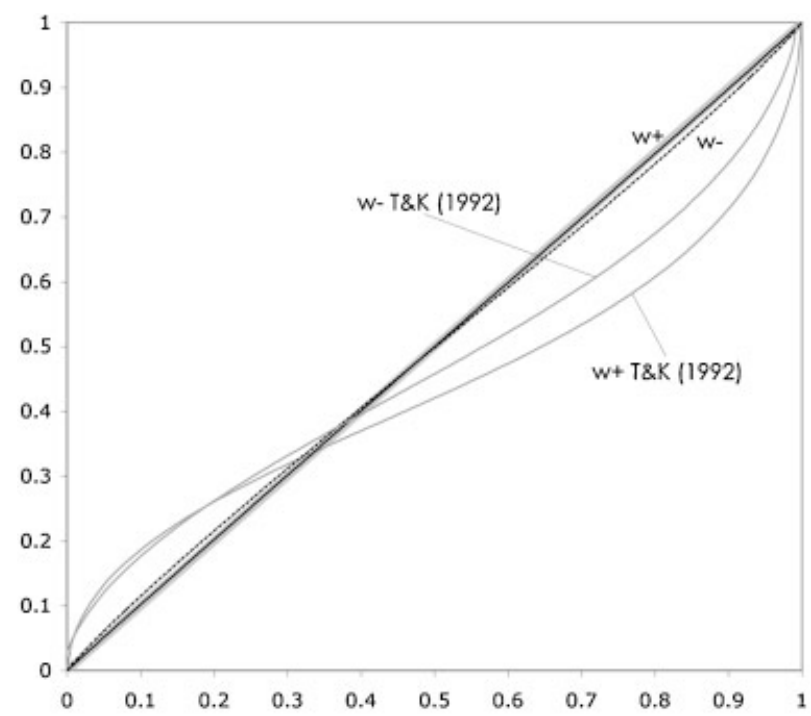

Figure 7. Weighting functions for decisions from description and decisions from experience. The weighting functions for gains $(\mathrm{w}+)$ and losses $(\mathrm{w}-)$, respectively, with the parameters estimated from Hertwig et al.'s (2004) data and Tversky and Kahneman (1992), respectively. Note that $w+$ is visually indistinguishable from the light gray diagonal that indicates linear weighting; w- is slightly more S-shaped

heuristic, and the natural-mean heuristic, appear to be promising candidate models. Third, several strategies achieved very similar performance, yet they did not simply make the same predictions. Take the two most successful strategies, maximax and the two-stage model with "experience" parameters. Both made the exact same number of correct predictions, but their predictions matched only in about $70 \%$ of all cases. This suggests that there may be no single "best" model describing all individuals best. Rather, it may be that people who tend to be more risk seeking are better described in terms of the maximax heuristic where the deck with the best possible outcome, no matter how likely it is, is chosen. Finally, using "experience" rather than "description" parameters for the two-stage model appears to boost the model's predictive performance. Experience parameters imply a linear weighting function for experienced probabilities.

Admittedly, our analysis is only a first step toward a better understanding of decisions from experience. Nevertheless, it identifies a number of tasks ahead such as clarifying the role of "experienced probabilities," and it points to a constructive competition between models embodying quite different policies in this choice domain. $^{7}$

\section{HOW TO DESCRIBE AND MODEL PEOPLE'S SEARCH BEHAVIOR}

In the model analysis, we focused on how to predict choices from the sampled information once search was over. Yet, we also made a number of observations about the sampling process that are worth summarizing and that could inform future analyses. One is symmetry. In Studies 1-3, we found that in 33, 26, and $20 \%$ of the trials, respectively, people sampled the exact same number of draws from both decks. Moreover, the median

\footnotetext{
${ }^{7}$ Following Hertwig et al. (2004), we probed for a recency effect by splitting all sample sequences in half and using the natural-mean heuristic to predict choices either from the first half or the last half of the sample. Contrary to previous findings (Hertwig et al., 2004, 2006), the difference between the two is negligible ( 58 vs. $60 \%, z=.757, n s$ ), indicating at best a very weak effect.
} 
deviation from perfect symmetry (in terms of equal-sized samples) was 6,6 , and 10 percentage points for the trials of Studies 1-3, respectively. Another property of search is the number of transitions between decks. In 49,35 , and $44 \%$ of trials in Studies 1-3, respectively, respondents chose to switch exactly once between the decks. They first sampled in one deck; then, they switched to the other, never to return to the first one. The tendency to do "first things first," rather than going back and forth, also became manifest in the small number of actual transitions relative to the maximum number of possible transitions between decks (given sample size $n$, the maximum number of transitions is $n-1$ ). The median ratio is $0.20,0.07$, and 0.08 in Studies $1-3$, respectively. Still another property of search is relative stability. For instance, a person's tendency to switch versus not-to-switch between decks proved relatively stable, with median correlations (between individuals' transition ratios across problems) of $0.78,0.62$, and 0.72 in Studies 1-3, respectively. Similarly, a person's tendency to sample extensively or to rely on small samples also appears relatively stable, with median correlations of 0.71 and 0.68 in Studies 1 and 2, respectively (in Study 3 all respondents were required to sample 100 times). The latter propensity has been shown by Rakow, Demes, and Newell (in press) to be related to interindividual differences in working-memory capacity.

\section{GENERAL DISCUSSION}

Experience matters. As Barron and Erev (2003), Gottlieb et al. (2007), Hertwig et al. (2004), Newell and Rakow (2007), and Weber et al. (2004) observed, decisions from experience and decisions from description can differ widely. In decisions from experience, small-probability events have less impact on people's choices than in decisions from descriptions. According to Hertwig et al. (2004), there are two reasons for this behavior: reliance on small samples and recency. People drew relatively small samples from the outcome distributions, thus risking underestimating the likelihood of rare events or not even encountering it. In addition, in the sequential sampling process, more recent outcomes had more impact on the final evaluation of the decks than they deserved (i.e., more than $1 / n$ ). In Study 1, we replicated reliance on small samples: People frequently undersampled the rare event and infrequently chose the deck favored by the rare event (Figure 4). In Studies 2 and 3, we boosted the size of the sample by providing higher stakes and by directing people's search. Now, the deck favored by the rare event was chosen more often than before. Nevertheless, there remained marked and systematic differences between the description and experience groups. In half of the problems of Studies 2 and 3, we found differences replicating those observed by Hertwig et al. (2004).

Why did these differences persist? Underestimating the probability of rare events is no longer a likely cause. In the large majority of samples in Studies 2 and 3 (75 and 90\%, respectively) participants experienced the rare events at least once. In addition, if anything, the sample probabilities of rare events were overestimated (Figure 3). Does the remaining description-experience gap result from recency? In fact, could recency perhaps even be more pronounced than in Hertwig et al. (2004) due to the substantially larger sequences of outcomes in Studies 2 and 3? We found little evidence for recency. (Footnote 7). Using only the second half of all samples to predict choices was not superior to using only the first half. Furthermore, the value-updating model that explicitly incorporates a recency parameter did not outperform other models that ignore serial position effects. This echoes a finding by Rakow et al. (in press), who found recency effects in only one of three experience conditions of their experiments, concluding that recency plays only a minor role in distinguishing between decisions from description and decisions from experience.

What then could explain the remaining description-experience gap? One factor that emerged from our studies is the distinct "treatment" of probabilities in decisions from description and experience, respectively. Our analysis of different models indicates that in decisions from experience, probabilities either (a) do not matter to people's choices at all (maximax heuristic), (b) are implicitly taken at face value (the natural-mean heuristic tracks the expected value without using an explicit representation of probabilities), or (c) are taken explicitly at face value (see the two-stage model's weighting parameters in Table 6). To illustrate the latter 
point consider Figure 7. It plots the weighting functions using the optimal parameters for the two-stage model derived from the data of Hertwig et al. (2004), relative to the weighting function of cumulative prospect theory using Tversky and Kahneman's (1992) estimates derived from decisions from description. The optimal parameters imply nearly linear treatment of probabilities. In other words, the characteristic pattern of overweighting of low-probability events, and underweighting of high-probability events, gauged from decisions from description, disappears in decisions from experience.

What does this mean for the ability of the two-stage model, and by extension, cumulative prospect theory to account for decisions from experience? In our view, the answer depends on what one believes to be the essence of cumulative prospect theory. If one understands its essence to be an algebraic model with parameters adjustable across a wide range, then the theory indeed performs well in predicting decisions from experience (Figure 6). Alternatively, one may see the theory's essence to be an elegant quantitative summary of well-known and robust behavioral phenomena observed in decisions from description, with parameter values that imply characteristic and psychologically meaningful forms of the value and probability weighting functions. On this view, the overweighting of rare events, implied by the inverse S-shape of the probability weighting function, is integral to cumulative prospect theory. In decisions from experience, such overweighting does not appear to occur. Consequently, one may conclude that the essence of prospect theory does not generalize to decisions from experience. People are doomed to disagree on how to interpret parameterized models such as prospect theory. For the time being, we believe that Hertwig et al.'s (2004) call for more than one theory of risky choices is not, as Fox and Hadar (2006) argued, premature.

\section{Limitations of the current studies}

In order to be able to compare the current set of results to past ones, we adopted the decision problems and the experimental methodology used previously. The benefit of comparability is, however, not without costs. In what follows, we discuss the potential limitations of the current studies, and, by extension, pointers to future studies.

\section{Limited set of problems}

In our studies, we used the same six decision problems investigated by Fox and Hadar (2006) and Hertwig et al. (2004), which in turn represent a subset of those used by Barron and Erev (2003). Having establishedusing this small set of problems - that the description-experience gap is not eliminated when people draw on large samples, one task ahead is to examine how robust and large the gap is across a wider range of problems, including mixed gambles, gambles with more than two outcomes, and gambles with a wider range of probabilities. Indeed, Ert and Erev (2007) and Yechiam and Busemeyer (2006) have already made steps in this direction, finding a tendency to underweight rare events across other problems; so did Erev, Glozman, and Hertwig (2008). The latter also identified two conditions that are likely to increase the impact of rare events, namely, when they become increasingly similar to comparison stimuli (constituting the context of a choice) and when they are explicitly presented.

Using a small set of problems renders it tempting to focus on modal choices per problem and on varying choice proportions per problem across studies. Because of the multiple sources of variance influencing decisions from experience, we resisted this temptation, focusing instead on the overall pattern. In decisions from description, there are at least two sources of variance, namely, variability across individuals and variability within the individual. Both sources of variability are likely to be amplified in decisions from experience. The same person may perceive the same decision problem differently, depending on how much information the person sampled. By analogy, different people may perceive the same decision problem differently, depending on how much information they sampled. Moreover, the stochastic nature of the sampling process means that choices vary as the same sampling behavior leads to randomly distorted 
samples. Take, for example, Problem 1 of Hertwig et al. (2004), in which people chose between "4 with a probability of .8 versus 3 for sure." In their experience group, participants chose the risky option $88 \%$ of the time, a proportion significantly larger than the 62\% observed in Study 1 (Table 1). Across the total of 229 draws from the risky-option deck made by all participants in Hertwig et al., the outcome "4" was experienced 194 times. That is, in $85 \%$ of all draws respondents saw " 4 " - a proportion that is significantly different from the objective probability (.8). In contrast, in Study 1, across the total of 189 draws from the same deck, " 4 " was experienced 153 times (81\%) - a close approximation of the objective probability. One needs to be careful not to read too much into this random variation in experience and in resulting choices.

\section{Model fitting on the aggregate level}

Due to the relatively small number of decision problems, we could not determine individual parameters for the two-stage model, the value-updating model, and the fractional-adjustment model. Rather, we fitted their parameters to the aggregate choice data. Admittedly, this is not an ideal way of fitting parameters as they are typically assumed to capture individual differences in, for instance, speed of learning, or the degree of overweighting of rare events. Again, this highlights the importance of studying more problems in the future and, in particular, of letting the same respondent make numerous choices to arrive at reliable individual-specific parameter estimates. Such a more encompassing set of problems should also include problems that, at least in theory, are designed to increase the chances of testing between the models considered here. In practice, however, the extent to which a specific decision problem yields diverging predictions depends to some extent on participants' information search.

\section{Model tests on the choice level}

We tested all 15 models against the observed choices. Some of them, however, are meant to model both choice and process. Therefore, they can be tested on those two levels: choice and process. For instance, if a heuristic such as maximax predicts choices well, it may still fail in describing the process, thus falsifying it as a process model. The natural-mean heuristic is an interesting case as on the level of choice it is tantamount to the expected value calculus. On the level of process, however, the heuristic and the calculus imply different processes. The latter assumes weighting (i.e., multiplication of outcomes with their respective probabilities) and summing. In contrast, the heuristic tots up all experienced rewards (or losses) per deck and divides this sum by the sample size per deck. It requires no explicit representation of the probability, and no weighting. Though this simpler process appears more psychologically plausible (and has been proposed in the context of $n$-armed bandit problems; see Sutton \& Barto, 1998), let us emphasize that our studies did not test this process. Until future experiments have tested the postulated process (also against the processes assumed by other models), the natural-mean heuristic is a model that predicts choice well, assuming a process that has not been tested.

\section{Lab versus online study, and incentives}

Let us conclude with one further possible limitation. Respondents in the description group of Study 1 completed an online questionnaire, whereas respondents in the experience groups in Studies 1-3 came to the lab; the former respondents also operated under a different payment scheme. These differences notwithstanding, our results and conclusions would be the same if we compared choices in the experience groups not only to those in the current online description group but also to those in the lab description group in Hertwig et al. (2004). This is consistent with the conjecture that in description-based choice, performance-contingent payoffs appear not to change choices markedly (e.g., Tversky \& Kahneman, 1992; but see Hertwig \& Ortmann, 2001) and that findings in lab and online studies of preferential choice using 
monetary gambles agree (Birnbaum, 1999). Future studies, however, should explore the impact of financial incentives, for instance, by keeping constant the rate of return across the two types of decisions.

\section{CONCLUSION}

Our findings suggest that representation matters. Although different representations of the same statistical information are mathematically equivalent (e.g., frequencies vs. probabilities), psychologically they are not. Experienced and described probabilities can be mathematically equivalent but psychologically they may trigger different cognitive strategies. In other words, the description-experience gap could be another manifestation of the important insight, that information representation shapes how people reason and how much risk they are willing to take (e.g., Gigerenzer \& Hoffrage, 1995; Gottlieb et al., 2007; Hoffrage, Lindsey, Hertwig, \& Gigerenzer, 2000; Tversky \& Kahneman, 1981).

\section{ACKNOWLEDGEMENTS}

Ralph Hertwig was supported by Swiss National Science Foundation Grant 100013-107741/1 and Timothy Pleskac was supported by National Institute of Mental Health Research Service Award (MH019879) awarded to Indiana University. We thank Robin Hogarth, Manuel Klimek, and Jörg Rieskamp for helpful comments on earlier drafts of the manuscript. We are also grateful to Laura Wiles for editing the manuscript.

\section{REFERENCES}

Allais, M. (1953). Le comportement de l'homme rationnel devant le risque: Critique des postulats et axiomes de l'école américaine. Econometrica, 21, 503-546.

Allais, M. (1979). The foundations of a positive theory of choice involving risk and a criticism of the postulates and axioms of the American school. In M. Allais, \& O. Hagen (Eds.), Expected utility hypotheses and the Allais paradox. (pp. 27-145). Dordrecht: Reidel.

Anderson, D. R. (1974). The national flood insurance program-problems and potential. Journal of Risk and Insurance, 41, 579-599.

Barron, G., \& Erev, I. (2003). Small feedback-based decisions and their limited correspondence to description-based decisions. Journal of Behavioral Decision Making, 16, 215-233.

Bernoulli, D. (1954). Exposition of a new theory on the measurement of risk. Econometrica, 22, 23-36. (Translation of Bernoulli, D. [1738]. Specimen Theoriae Novae de Mensura Sortis. Papers of the Imperial Academy of Sciences in St. Petersburg, 5, 175-192.)

Birnbaum, M. H. (1999). Testing critical properties of decision making on the internet. Psychological Science, 10, 399-407.

Brandstätter, E., Gigerenzer, G., \& Hertwig, R. (2006). The priority heuristic: Making choices without trade-offs. Psychological Review, 113, 409-432.

Busemeyer, J. R., \& Myung, I. J. (1992). An adaptive approach to human decision-making learning-theory, decision-theory, and human-performance. Journal of Experimental Psychology. General, 121, 177-194.

Busemeyer, J. R., \& Wang, Y. M. (2000). Model comparisons and model selections based on generalization criterion methodology. Journal of Mathematical Psychology, 44, 171-189.

Bush, R. R., \& Mosteller, F. (1955). Stochastic models for learning. New York: Wiley.

Dawes, R. M. (1979). The robust beauty of improper linear models in decision making. American Psychologist, 23, 571-582.

Denrell, J. (2007). Adaptive learning and risk taking. Psychological Review, 114, 177-187.

Edwards, W. (1954). The theory of decision making. Psychological Bulletin, 51, 380-417.

Ellsberg, D. (1961). Risk, ambiguity, and the savage axioms. Quarterly Journal of Economics, 75, 643-669. 
Erev, I., \& Barron, G. (2005). On adaptation, maximization, and reinforcement learning among cognitive strategies. Psychological Review, 112, 912-931.

Erev, I., Glozman, I., \& Hertwig, R. (2008). What impacts the impact of rare events. Journal of Risk and Uncertainty, 36, 153-177. DOI: $10.1007 / \mathrm{s} 11166-008-9035-2$

Ert, E., \& Erev, I. (2007). Replicated alternatives and the role of confusion, chasing, and regret in decisions from experience. Journal of Behavioral Decision Making, 20, 305-322.

Estes, W. K. (1959). The statistical approach to learning. In S. Koch (Ed.), Psychology: A study of a science Vol. 2 (380-491). New York: McGraw-Hill.

Fox, C. R., \& Hadar, L. (2006). Decisions from experience = sampling error + prospect theory: Reconsidering Hertwig, Barron, Weber \& Erev (2004). Judgment and Decision Making, 1, 159-161.

Fox, C. R., \& Tversky, A. (1998). A belief-based account of decision under uncertainty. Management Science, $44,879$.

Gigerenzer, G., \& Hoffrage, U. (1995). How to improve Bayesian reasoning without instruction: Frequency formats. Psychological Review, 102, 684-704.

Gottlieb, D. A., Weiss, T., \& Chapman, G. B. (2007). The format in which uncertainty information is presented affects decision biases. Psychlogical Science, 15(3), 240-246.

Hacking, I. (1975). Emergence of probability. Cambridge: Cambridge University Press.

Harrison, G. W. (1989). Theory and misbehavior of first-price auctions. American Economic Review, 79, 749-762.

Hertwig, R., Barron, G., Weber, E. U., \& Erev, I. (2004). Decisions from experience and the effect of rare events in risky choice. Psychological Science, 15, 534-539.

Hertwig, R., Barron, G., Weber, E. U., \& Erev, I. (2006). The role of information sampling in risky choice. In K. Fiedler, \& P. Juslin (Eds.), Information sampling and adaptive cognition. (pp. 75-91). New York: Cambridge University Press.

Hertwig, R., \& Ortmann, A. (2001). Experimental practices in economics: A methodological challenge for psychologists? Behavioral and Brain Sciences, 24, 383-451.

Hertwig, R., Pachur, T., \& Kurzenhäuser, S. (2005). Judgments of risk frequencies: Tests of possible cognitive mechanisms. Journal of Experimental Psychology: Learning, Memory, and Cognition, 31, 621-642.

Hertwig, R., \& Pleskac, T. J. (2008). The game of life: How small samples render choice simpler. In N. Chater, M. Oaksford, (Eds.), The probabilistic mind: Prospects for rational models of cognition (pp. 209-236). Oxford, UK: Oxford University Press.

Hoffrage, U., Lindsey, S., Hertwig, R., \& Gigerenzer, G. (2000). Communicating statistical information. Science, 290, 2261-2262.

Kahneman, D., \& Tversky, A. (1979). Prospect theory: An analysis of decision under risk. Econometrica, 47, 263291.

Klein, G. (1998). Sources of power: How people make decisions. Cambridge, MA: The MIT press.

Koehler, J. J. (1996). The base rate fallacy reconsidered: Descriptive, normative, and methodological challenges. Behavioral and Brain Sciences, 19, 1-53.

Kunreuther, H. (2006). Disaster mitigation and insurance: Learning from Katrina. The Annals of the American Academy of Political and Social Science, 604, 208-227.

Luce, R. D., \& Raiffa, H. (1957). Games and decisions. New York: Wiley.

March, J. G. (1996). Learning to be risk averse. Psychological Review, 103, 309-319.

Munich Re Group, Münchener Rück. (2006). Hurrikane-stärker, häufiger, teurer. München: Münchener Rück.

Newell, B. R., \& Rakow, T. (2007). The role of experience in decisions from description. Psychonomic Bulletin and Review, 14, 1133-1139.

Payne, J. W., Bettman, J. R., \& Johnson, E. J. (1993). The adaptive decision maker. New York: Cambridge University Press.

Rakow, T., Demes, K., \& Newell, B. (in press). Biased samples not mode of presentation: Re-examining the apparent underweighting of rare events in experience-based choice. Organizational Behavior and Human Decision Processes.

Savage, L. J. (1954). The foundations of statistics. New York: John Wiley \& Sons.

Slovic, P., Fischhoff, B., Lichtenstein, S., Corrigan, B., \& Combs, B. (1977). Preference for insuring against probable small losses: Insurance implications. Journal of Risk and Insurance, 44, 237-258.

Smith, V. L. (1982). Microeconomic systems as an experimental science. American Economic Review, 72, 923-955.

Sutton, R. S., \& Barto, A. G. (1998). Reinforcement learning: An introduction. Cambridge; MA: The MIT Press.

Thorngate, W. (1980). Efficient decision heuristics. Behavioral Science, 25, 219-225.

Trope, Y., \& Liberman, N. (2003). Temporal construal. Psychological Review, 110, 403-421.

Tversky, A., \& Fox, C. R. (1995). Weighing risk and uncertainty. Psychological Review, 102, 269-283.

Tversky, A., \& Kahneman, D. (1981). The framing of decisions and the psychology of choice. Science, $211,453-458$.

Tversky, A., \& Kahneman, D. (1992). Advances in prospect theory: Cumulative representation of uncertainty. Journal of Risk and Uncertainty, 5, 297-323. 
von Winterfeldt, D., \& Edwards, W. (1986). Decision analysis and behavioral research. New York: Cambridge University Press.

Weber, E. U., Boeckenholt, U., Hilton, D. J., \& Wallace, B. (1993). Determinants of diagnostic hypothesis generation: Effects of information, base rates, and experience. Journal of Experimental Psychology: Learning, Memory, and Cognition, 19, 1151-1164.

Weber, E. U., Shafir, S., \& Blais, A.-R. (2004). Predicting risk sensitivity in humans and lower animals: Risk as variance or coefficient of variation. Psychological Review, 111, 430-445.

Yechiam, E., Barron, G., \& Erev, I. (2005). The role of personal experience in contributing to different patterns of response to rare terrorist attacks. Journal of Conflict Resolution, 49, 430-439.

Yechiam, E., \& Busemeyer, J. R. (2006). The effect of foregone payoffs on underweighting small probability events. Journal of Behavioral Decision Making, 19, 1-16.

Authors' biographies:

Robin Hau is a doctoral student of Cognitive and Decision Sciences in the Department of Psychology at the University of Basel, Switzerland. His research focuses on experience-based decisions and cognitive modeling.

Timothy J. Pleskac is an Assistant Professor of Applied Cognitive Science in the Department of Psychology at Michigan State University. His research focuses on developing formal cognitive models in the area of cognitive decision theory.

Jüergen Kiefer did his Ph.D. as a student of the graduate program "prometei" at the Center of Human-Machine Interaction, TU Berlin, and is now senior researcher and project leader at the usability company, eye square. His interests focus on human multitasking, human-computer interaction, usability, and intuitive design.

Ralph Hertwig is Professor of Cognitive and Decision Sciences in the Department of Psychology at the University of Basel, Switzerland. His research focuses on models of bounded rationality, social intelligence, and methodology of the social sciences.

Author's addresses:

Robin Hau, Department of Psychology, University of Basel, Missionsstrasse 64a, 4051 Basel, Switzerland.

Timothy J. Pleskac, Department of Psychology, Michigan State University, USA.

Jüergen Kiefer, Center of Human-Machine-Systems, Technical University, Berlin, Germany.

Ralph Hertwig, Department of Psychology, University of Basel, Switzerland. 